\title{
Seroprevalence of bluetongue antibodies among goats in selected small ruminant farms in Serdang, Malaysia
}

\begin{abstract}
Bluetongue disease is an arthropod-transmitted viral disease of ruminants with a worldwide distribution. Bluetongue outbreaks has been reported among livestock in Malaysia during the 1990s and since then few studies have paid attention to the status of Bluetongue in Malaysia. The aim of this study was to determine the seroprevalence of antibodies to bluetongue virus among goats in selected small ruminant farms in Selangor, Malaysia. Blood samples were collected from 100 randomly selected goats. Sera were harvested and used for antibody detection. The result obtained revealed that all the samples tested were negative for antibodies to bluetongue virus. It was concluded that the goats sampled in this study were not exposed to bluetongue virus. Further studies using a bigger sample size, multiple species and a larger study area will be required to elucidate on the epidemiology of bluetongue virus in livestock of Malaysia.
\end{abstract}

Keyword: Antibodies; Bluetongue virus; Goat; Seroprevalence; Serum 